\title{
«YOU SAVED HER LIFE AND SHE ADORES YOU FOR IT»: LA BUENA SALVAJE EN EL MELODRAMA INGLÉS DE LOS 1860
}

\author{
VICTORIA PUCHAL TEROL \\ Universidad Católica de Valencia «San Vicente Mártir»*
}

\begin{abstract}
Resumen
El origen del personaje tipo del buen salvaje o noble savage se remonta a 1672, cuando John Dryden atribuyó cierta cualidad de pureza o libertad al salvaje que vivía ajeno a la civilización. Más adelante, el filósofo francés Jean Jacques Rousseau (1754) definió al buen salvaje como un ser inocente y no corrupto. Aunque el buen salvaje ha sido principalmente representado como hombre, también existen figuras femeninas que siguen el mismo patrón. El presente artículo pretende arrojar luz sobre la representación de la buena salvaje en el teatro de sensaciones o sensation drama de Londres a mediados del siglo XIX. Tras revisar la figura del buen salvaje, sus alternativas femeninas y su consiguiente iconografía, se ofrecen dos estudios de caso: las obras anónimas Cahontas, the Delaware's Daughter (1860) y The Prairie Flower (1860). Las protagonistas de estas obras de ambientación western nos permitirán explorar la representación y percepción pública de la buena salvaje.

Palabras clave: buen salvaje, buena salvaje, melodrama, obras de sensaciones, teatro.

\section{"YOU SAVED HER LIFE AND SHE ADORES YOU FOR IT»: THE FEMALE NOBLE SAVAGE IN THE ENGLISH MELODRAMA OF THE $1860 \mathrm{~S}$}

\begin{abstract}
The origin of the «noble savage» dates back to 1672, when John Dryden identified in the uncivilised «savage» the qualities of purity and carelessness. Later, the French philosopher Jean Jacques Rousseau (1754) defined the noble savage as an innocent, uncorrupted being. Even though the noble savage has been usually represented as man, we can

* La investigación que se ha realizado para este artículo ha sido financiada por el proyecto FFI2017-86417-P y el grupo GIUV 2017-354.
\end{abstract}


also find female noble savages in literature. This article examines the representation of the female noble savage in London's sensation drama of the mid-nineteenth century. We first propose to review the figures of both the male and female noble savages, considering also their popular iconography. We offer then two case studies: the anonymous works Cahontas, the Delaware's Daughter (1860) and The Prairie Flower (1860). The protagonists of these Western plays will give us the opportunity to explore the representation and public perception of the female noble savage.

Keywords: noble savage, female noble savage, melodrama, sensation plays, theatre.

\section{INTRODUCCIÓN}

En 1863 los exploradores y geógrafos John Speke y James Grant fueron recibidos con honores en la Royal Geographical Society de Londres tras anunciar su descubrimiento del nacimiento del río Nilo. Los periódicos de la ciudad relataron su hazaña y vitorearon, una vez más, la valentía de los viajeros, naturalistas y soldados ingleses posicionados en las colonias del Imperio británico. Después de todo, se trataba de un motivo de orgullo nacional. Sin embargo, durante el acto de bienvenida de Speke y Grant a la capital, un protagonista inesperado acaparó las miradas: el joven africano de catorce años que acompañaba al Capitán Speke. El periódico The Globe (23 de junio de 1863) describía al joven como «an excellent specimen of the intelectual black type» y el mismo Speke afirmaba que su descubrimiento no habría sido posible sin la ayuda del muchacho. Con la mirada puesta en las colonias, Speke insistía en la necesidad de educar a los «africanos más inteligentes" para poder así disponer de ellos como cónsules y sirvientes en el futuro; en definitiva, se pretendía transformar a los nativos más «válidos» en aliados del Imperio británico.

La actitud de Speke hacia el joven sin duda se asemeja a lo que John Dryden bautizó en 1672 como «noble savage» o «buen salvaje». Como antítesis del «salvaje» común, el estereotipo del «buen salvaje» se utiliza con asiduidad en las adaptaciones victorianas de relatos conocidos como Oroonoko de Aphra Behn, publicada en 1688, o Robinson Crusoe de Daniel Defoe, en 1719. El joven acompañante de Speke muestra el paradigma de todo lo que el buen salvaje debía ser según la literatura decimonónica: por lo general, se trata de un joven sudamericano, africano, nativo americano o indio. En los relatos de viajes, el buen salvaje 
acompaña al héroe blanco e interpreta el papel de "amigo», pero siempre desde una posición de desventaja. Como Friday en Robinson Crusoe, ejemplo del buen salvaje en la literatura por antonomasia, renuncia también a sus creencias para seguir las costumbres del colono blanco. Es, como diría Rousseau, un ser pre-social, sin leyes (Jáuregui, 2008: 225).

Ellingson (2011) ofrece una interesante reflexión sobre el mito del buen salvaje o noble savage durante mediados del siglo XIX. De acuerdo con su estudio, el buen salvaje se convierte en una aparente paradoja a raíz de los estudios etnográficos y antropológicos decimonónicos. Sobre el papel, autores como James Greenwood o John Jeffries califican al salvaje como "a child of nature» $\mathrm{o}$ indican que «some savages are nobler than others» (Ellingson, 2011: 215-216). Así, se promueve una clasificación de las razas y etnias y se establece una dicotomía en el carácter del "Otro» ${ }^{1}$, quien es "by turns gentle, in tune with nature, paradisal, ideal -or violent, in need of control; what we should emulate or, alternately, what we should fear; noble savages or cannibals» (Flint, 2009: 5).

Como veremos en este artículo, aunque el buen salvaje ha sido generalmente representado como hombre en la literatura, también existen ejemplos de la «buena salvaje» mujer. Ambos sexos muestran una actitud casi patológica de reverencia hacia el protagonista, llegando incluso a referirse a él como si de una deidad se tratase. En el caso de la buena salvaje, lo más habitual es que además de toda la relación de admiración, ella se enamore de él. Además, la buena salvaje suele ser considerada una «belle sauvage», materializando y sexualizando así los deseos de conquista colonial (McClintock, 1995: 14). Tal y como demuestran las dos obras seleccionadas para nuestro análisis en el presente artículo, la buena salvaje se ve envuelta en una trama romántica no correspondida, tumultuosa y, habitualmente, con final fatídico para ella.

${ }^{1}$ Según los estudios postcoloniales, el término «Otro» hace referencia al nativo que no es blanco y, por tanto, está fuera de la sociedad occidental blanco-céntrica. En este artículo se utiliza el término "Otro» siguiendo la teoría de Said (1978), que fundamenta el colonialismo e imperialismo modernos en el orientalismo; es decir, la tendencia occidental a designar como diferente al que no es como él. Esta diferenciación entre «nosotros/ellos» y «blanco/no blanco» se produce en detrimento del más débil en la escala jerárquica. Otros autores cuyas contribuciones se han tenido en cuenta para nuestro análisis son Bhabha (1994), Spivak (1988) y Pratt (1992). 
En la siguiente sección ahondaremos en la cuestión del buen salvaje o «noble savage», haciendo especial hincapié en su representación en la literatura y el teatro decimonónicos. Como veremos, el contexto sociohistórico colonial de Inglaterra a mediados del diecinueve propicia un cambio en el paradigma del buen salvaje; nuevas teorías evolucionistas como la de Charles Darwin y su Origin of Species (1859), además del debate racial ocasionado por la Guerra Civil americana (1861-1865) y las contiendas del Imperio británico durante sus conquistas, hacen que en la capital el interés esté puesto en lo «Otro», lo «exótico», lo alterno. Por esa razón, en su representación del buen salvaje, la ficción de mediados de siglo XIX entremezcla la concepción rousseauniana del salvaje como ser puro e inocente y las tendencias etnológicas y antropológicas supremacistas ante el «Otro».

En la tercera y última sección se comentan las convenciones propias del teatro melodramático victoriano y del género «sensation» o sensacionalista de los 1860, haciendo referencia a la representación de la raza y, además, proponiendo dos estudios de caso en los que se utiliza el estereotipo de la buena salvaje. Se pretende arrojar luz sobre la cuestión de la representación racial en un género teatral de gran reclamo, además de poner en valor las herramientas del teatro popular de mediados de siglo para enseñar y/o adoctrinar a las masas. Las obras en cuestión son las anónimas Cahontas, the Delaware's daughter, del teatro City of London, y The Prairie Flower, del Britannia Theatre. Estas dos obras melodramáticas de ambientación western fueron estrenadas en Londres en 1860 con meros meses de diferencia (abril en el caso de la primera y noviembre en el de la segunda). Las similitudes entre ambas no son escasas: las dos están dirigidas a un público de clase trabajadora, fueron llevadas a escena en el East End londinense, llevan por título el nombre o apodo de una mujer nativa americana y están basadas en relatos muy conocidos por el público de la época. Como se demostrará en la tercera sección del presente artículo, las protagonistas de nuestros estudios de caso, Cahontas y Zuletta, nos ofrecen un interesante preámbulo desde el cual podemos estudiar el personaje tipo de la buena salvaje en la escena del diecinueve. 


\section{EL BUEN SALVAJE A MEDIADOS DEL SIGLO XIX}

Las décadas de los 1850 y 1860 estuvieron caracterizadas por la cantidad de conflictos de ultramar a los que el Imperio británico tuvo que hacer frente. Además de la Rebelión de la India en 1857, en la que los soldados indios amotinados atacaron los asentamientos ingleses, otros conflictos de larga duración, como las Guerras de las Tierras de Nueva Zelanda (1845-1872) y la Segunda Guerra Anglo-Asante (1863-1864), hicieron que en todo el país se hablase de las barbaries a las que muchos compatriotas se estaban viendo sometidos. A pesar de las múltiples victorias de los soldados británicos y del ensalzamiento del imperio, conflictos como los anteriormente mencionados hicieron que durante la mitad del siglo XIX predominara un sentimiento de desconfianza y sospecha ante el «Otro». Es por esto por lo que, a lo largo de los 1850 y 1860, los avances coloniales se justificaran como viajes de «civilización de sujetos» (Hall, 2002) o de «domesticación» de los salvajes (Brantlinger, 2011). El ideario patriótico y nacionalista del país se vio alimentado por una proliferación de representaciones racistas en los géneros y medios populares, que pronto adoptaron ciertos estereotipos y recursos como los «minstrels shows» o el conocido personaje tipo de Jim Crow. Tal y como apunta Waters (2007: 95), este tipo de representaciones tenían el objetivo de retomar el control sobre el «Otro», de ridiculizar al nativo de las colonias contra los que muchos soldados peleaban en otra parte del mundo, para así borrar su aspecto amenazante y hacer sentir al público británico que no había nada que temer.

Sin embargo, la posición de los británicos ante la cuestión racial durante mediados de siglo se torna contradictoria; a la vez que la corriente abolicionista recorría el país a raíz de la incipiente Guerra Civil americana, el miedo hacia el «Otro» se extendía. Según Daly (2013: 11), esto se debía no solo a los sucesos en las colonias, sino también a los conflictos sociales que estaban ocurriendo en Londres durante la década, los cuales amenazaban con cambiar la sociedad y dar un repaso a la jerarquía de clases. Asimismo, Brantlinger (2011: 112) relaciona la desconfianza ante los individuos racializados con los debates sobre evolución que surgieron tras la publicación del Origin of Species (1859) de Darwin, y de On the Negro's Place in Nature (1863), escrito por el antropólogo James Hunt. Este último, cofundador de la Sociedad Antropológica de Londres, ya 
había rechazado las teorías evolucionistas de Darwin; según Hunt, cada raza tenía un origen diferente y, por tanto, no había posibilidad de equiparar al resto de las razas con la anglosajona. En definitiva, los debates raciales produjeron una categorización de los individuos, propiciando una clasificación según la moralidad y la capacidad intelectual y física del sujeto.

Esta clasificación fue perpetuada por la oferta cultural del momento. Sin duda, la cuestión racial influyó en la representación de los personajes racializados para el entretenimiento y en la ficción decimonónicos; como indican Hardt y Negri (2002: 105):

la identidad del pueblo se construyó sobre un plano imaginario que ocultó y/o eliminó las diferencias y, en el plano práctico, esto se tradujo en la subordinación racial y la purificación social. La segunda operación fundamental en la construcción del pueblo, facilitada por la primera, consistió en eclipsar las diferencias internas haciendo que un grupo, una clase o una raza hegemónica representara a la población en su conjunto.

En Londres, la oferta de espectáculos en los que se explotaba de alguna manera lo «exótico» o lo extranjero se acrecentó; antes de los 1860 la ciudad había dado cabida a exposiciones humanas o "zoos humanos» en los que se exhibía grupos de nativos, humanos reales traídos desde las colonias (Qureshi, 2011; Sánchez-Gómez, 2013). Como el periódico Illustrated London News sugiere (12 de junio de 1847), estos espectáculos pretendían mostrar "the two extremes of humanity», poniendo a los británicos cara a cara con los «sujetos» a los que aún debían civilizar.

Parece ser que el debate racial de mediados de siglo fue lo que trajo de vuelta el estereotipo del buen salvaje. Es indudable que el éxito de novelas como Uncle Tom's Cabin (1852) de Harriet Beecher Stowe avivó el movimiento abolicionista en Inglaterra. A raíz de la novela sensacionalista, el negro reformista se convirtió en un arma de doble filo para los críticos: por un lado, este evidenciaba la falsa democracia americana y, por otro, rescataba la imagen del buen salvaje de los Románticos (Taylor, 1961: 46). A ojos de los británicos, se trataba, de nuevo, de un problema de civilización. 
A raíz de los acontecimientos y de las revueltas, Charles Dickens escribió The Noble Savage. Publicado el 11 de junio de 1853, el texto cuestiona la existencia del «buen salvaje» (Dickens, 1853: 337-339):

I have not the least belief in the Noble Savage. I consider him a prodigious nuisance, and an enormous superstition... I call him a savage, and I call a savage a something highly desirable to be civilised off the face of the earth... if we have anything to learn from the Noble Savage, it is what to avoid.

Según apunta Flint (2009: 144), en su alegato en contra del buen salvaje, Dickens habría sido influenciado por los relatos y los espectáculos humanos de George Catlin, uno de los principales historiadores y escritores sobre costumbres nativo-americanas de la época. Sus pinturas, escritos y espectáculos de «tableaux vivants» sentaron precedente en Inglaterra durante los 1840, convirtiéndose en referencia para los «wild West shows» y espectáculos «de salvajes» futuros de mediados de siglo. Como Dickens, muchos victorianos no acababan de creerse que los individuos que se exhibían fueran extraordinarios, buenos, o nobles; más bien, todo lo contrario. Según Altick (1978: 279-281), para el público que asistía a estos espectáculos el buen salvaje no era más que una confirmación de sus sospechas y prejuicios: los anglosajones seguían quedando por encima en la jerarquía racial.

En cuanto a los personajes femeninos racializados, existe también una tradición de estereotipación sobre los escenarios decimonónicos. Mabilat (2008: 65-83) comenta la polarización de la «Otra» mujer y destaca su habitual dicotomía entre ángel/demonio. Eltis (2013: 9) apunta que algunos eufemismos como "soiled dove», o el más conocido «fallen woman», eran comúnmente utilizados para referirse a aquellas mujeres cuya reputación había sido «manchada» por algún tipo de transgresión -a menudo, sexual-. Estos epítetos pretendían juzgar y apartar a las mujeres que no seguían las normas de feminidad marcadas. De igual manera, los estudios de caso sugieren que la salvaje, a menudo, también ocupa un espacio liminal en el que no acaba de definirse como buena; en otras palabras, que resulta difícil de definir. El interés en las colonias del este lleva a los dramaturgos y escritores de mediados de siglo XIX a sexualizar la imagen de los personajes femeninos del Este -como indican Mabilat (2008: 68) y Pal-Lapinski (2005), se representa el cuerpo de la 
mujer «oriental» de manera sensual, como una femme fatale-. En cambio, el caso de las nativas americanas o de las mujeres de América del Sur que aparecían en los relatos coloniales o de viajes es diferente. Lyytinen (2009: 78) destaca el ejemplo de Pocahontas, la princesa Powhatan. Si bien Pocahontas ha sido tratada por la historia como una protagonista trágica, «madre» de la civilización, también ha servido para reforzar la imagen de la buena y «bella salvaje» $\mathrm{O}$ «belle savage». Al igual que sugiere Mabilat (2008) con su teoría de la dicotomía de la «Otra», Lyytinen argumenta que obras populares como The Indian Princess, or La Belle Sauvage (1808) de James Nelson Barker o Pocahontas, or The Gentle Savage (1855), de John Brougham, rescataron y perpetuaron la imagen de «buena India», «bella salvaje» $y$, en definitiva, «buena salvaje» de la nativa americana.

De esta manera, es común encontrar escenas de inspiración colonial y personajes femeninos abiertamente racistas en el teatro popular inglés -especialmente en aquellos géneros subversivos como el burlesque o el music hall-. En la ficción, generalmente, el carácter del buen salvaje va de extremo a extremo, de solemne a pintoresco, pasando por degenerado e incluso peligroso a veces (Mabilat, 2008). En el teatro, las historias del buen salvaje se utilizan con fines moralistas (Chambers, 2011: 25). Como hemos mencionado anteriormente, el personaje tipo del salvaje sobre los escenarios decimonónicos se representa de manera extrema y categorizada. Existe una diferenciación clara entre las razas «peligrosas» (árabes e indias) y las "cómicas» (nativas americanas, africanas y chinas) (Waters, 2007: 95). Así, los relatos sensacionalistas en el teatro explotan la figura del temido «Moor» o del «Turk» y se aprovechan del interés por lo exótico (Ziter, 2003). Fuera del teatro, los decimonónicos habían sido testigos de una tradición iconográfica del «Otro», lo cual había creado un sentimiento generalizado de conocimiento. Para los espectadores de las clases sociales más bajas, el entretenimiento en general y el teatro popular en particular se había convertido en fuente de información; por tanto, la representación de los personajes racializados tenía una influencia inequívoca sobre la sociedad. Como veremos a continuación, la cuestión de la buena salvaje durante los 1860 permite a los dramaturgos comentar los temas sociales del momento y, a su vez, perpetuar los estereotipos de la «Otra». 


\section{LA BUENA SALVAJE EN EL MELODRAMA DE LOS 1860}

El teatro melodramático y en especial el «sensation drama» de mediados del siglo XIX siente predilección por la trágica historia de la mujer nativa en el contexto colonial. Las historias de aventuras y los relatos de viajes cobran tintes melodramáticos una vez son adaptados sobre el escenario. Así, la trama secundaria de la mujer nativa o la buena salvaje sirve a los dramaturgos para enmarcar las peripecias del protagonista masculino, quien está demasiado ocupado luchando contra «salvajes» y yendo en busca de civilización. Como nuestros estudios de caso sugieren, la buena salvaje modifica su existencia e identidad personal una vez conoce al héroe colono o viajero blanco. En primer lugar, analizaremos el personaje de Cahontas, una de las muchas apropiaciones en la ficción victoriana del conocido personaje Pocahontas, la princesa nativa americana. A continuación, rescataremos el personaje de Zuletta, la «prairie flower» $\mathrm{o}$ "flor de la pradera», una nativa americana cuyo apodo da nombre a una novela western de Gustave Aimard y a la obra melodramática homónima que aquí veremos.

Como se ha comentado anteriormente, en el teatro la cuestión de la raza encuentra cabida en los personajes tipo que son explotados dentro de cada género. Los estereotipos de personajes racializados siguen las convenciones de los géneros teatrales -cómicos en el caso del teatro popular, extremistas y malignos en el del drama- y adoptan ciertos manierismos, vestuario y lenguaje que les hacen ser fácilmente reconocibles por el público. Además, la mayoría de los personajes racializados son interpretados por actores y actrices blancos actuando en «blackface» o «brownface». En los teatros, y especialmente en la escena melodramática, se animaba al público a suspender su escepticismo y dejarse llevar por el choque de sensaciones típico de las tramas del melodrama (Voskuil, 2004: 73). Aunque el género melodramático no era algo nuevo (llevaba cosechando éxitos en escena desde principios del siglo XIX), el auge de las «sensation plays» u obras de sensaciones de los 1850 y 1860 hizo que grandes obras cuyo tema central era el de la raza marcaran tendencia durante el resto de la década. Estas, además de ser sugerentes y atrevidas, permitían que el público asimilara de una manera diferente los temas sociales candentes del momento. Según Diamond (2003: 218-219), el 
«sensation drama» estaba plagado de «sensation scenes» o escenas de gran impacto:

To qualify as a sensation drama, a play had to contain one or more 'sensation scenes' showing overwhelming experience, often a disaster -a fire, a earthquake, an avalanche, a shipwreck, a train crash. (Murder had always featured in melodrama of all kinds.)... Sensation scenes were exciting in themselves, but the audience also marvelled at the technical feat involved in replicating aspects of life that seemed beyond the resources of the stage. Eventually, the term 'sensation scene' referred to any lavishly mounted sequence in a melodrama which took the audience's breath away, or any scene of intense emotional upheaval.

Algunas de las obras de sensaciones más repuestas en Londres eran precisamente populares por su alto contenido en este tipo de escenas; por ejemplo, Slave Life (1852), de Mark Lemon y Tom Taylor para el Adelphi, adaptaba la exitosa novela de Beecher Stowe que tanto había dado que hablar, y la escena de venta de esclavos en The Octoroon (1859) de Dion Boucicault, apelaba a las emociones de un público que tan concienciado estaba en contra de la esclavitud ${ }^{2}$. Asimismo, los dramaturgos de mediados de siglo reinterpretaban hasta la saciedad novelas, historias o relatos populares, casi siempre de una manera bastante libre (Meer, 2018; Curry, 2019). De esta manera, las historias de sus buenos y buenas salvajes protagonistas eran reconfiguradas según el contexto sociohistórico, llegando a ser determinantes en la formación del ideario colonial de la época.

El interés de los británicos por los nativos americanos durante los 1860 no era algo nuevo. Según indica Stoner (2003: 509), la Pocahontas de John Smith (1624) sirvió de inspiración para la ficción del siglo XIX en ambos lados del atlántico, seguramente debido a su argumento romántico y a sus tintes históricos. En Inglaterra, Sir Walter Scott ya habría advertido en 1822 sobre el potencial que tenía la historia de Pocahontas, siempre y cuando cayera en manos de un buen conocedor de las costumbres nativas y de la vida en la frontera (Dyer, 2008). En Londres, durante

${ }^{2}$ En 1851, durante la Great Exhibition en el Crystal Palace de Londres, la escultura con tintes abolicionistas "The Greek Slave», del escultor americano Hiram Powers, se convirtió en el telón de fondo de representaciones en las que fugitivos afroamericanos abogaban por la abolición de la esclavitud (The Illustrated Exhibitor, 1851). Davis (2012: 18) sugiere que, detrás de la solidaridad que los británicos sentían por los esclavos afroamericanos, se escondía el rencor por haber perdido las colonias en el siglo XVIII. 
los 1840, el Egyptian Hall, una conocida sala de exposiciones y eventos decorada al estilo egipcio, había exhibido imágenes y objetos nativos americanos y celebrado numerosas actuaciones con nativo americanos reales traídos desde América, llegando incluso a celebrar pases privados para la reina Victoria (Altick, 1978: 276-277).

En Cahontas, or the Delaware's Daughter ${ }^{3}$, la historia trágica de Pocahontas se transforma en sensacionalista al narrar un caso de bigamia. Según los sucesos en esta adaptación del City of London, Cahontas se casa con Rolfe, un colono blanco, después de que este erróneamente diera a su mujer y a sus hijos por muertos tras un trágico suceso. De acuerdo con las convenciones de la buena salvaje, Cahontas es la única de su tribu que se muestra sensata ante la llegada de los colonos, llegando a interceder por los británicos y, al final, por el héroe de la historia, Rolfe:

Poтомac: I see the cause of this. The pale faced English have sent the poison from their own crowded land into our woods and forests to rob us of the obedience of our women.

CAHONTAS: 'tis false. The English have been to us law guides and we have but to practise what they have taught tmjo become like them, a mighty people (f. 5) ${ }^{4}$.

Cahontas recuerda al público su condición de buena salvaje por su carácter conciliatorio; como indica Green (1975: 704), para ser «buena», históricamente el personaje tipo de Pocahontas «must defy her own people, exile herself from them, become White, and perhaps suffer death». La obra del City of London continúa ofreciéndonos una visión dicotomizada de la princesa Cahontas: por un lado, sumisa y servicial con Rolfe, el colono; por otro, activa, salvaje. Sobre el escenario, Cahontas se mueve con total libertad, deleitando al público con imágenes al más puro estilo romántico en las que se hace valer por sí sola en plena naturaleza,

\footnotetext{
${ }^{3}$ Las citas directas a la obra que se utilizan en esta sección corresponden a los folios numerados del manuscrito original conservado en la British Library de Londres, con referencia British Library Add. MS 52992 F: «Cahontas, the Delaware's daughter. Drama in two acts. City of London, 18 abril 1860». No existe versión editada impresa del guion.

${ }^{4}$ Todas las traducciones de las citas directas de las obras son propias: «P: Ya veo la razón de todo esto. Los rostros pálidos de los ingleses han traído el veneno desde sus propias tierras a nuestros bosques para despojarnos de la obediencia de nuestras mujeres. C: Eso es mentira. Los ingleses han sido guías legales para nosotros, solo debemos poner en práctica lo que nos han enseñado para poder ser como ellos, un pueblo poderoso».
} 
escalando rocas y salvando a una paloma de ser devorada por un águila. De acuerdo con su posición social de mujer, Cahontas debe responder primero ante su padre, el líder de la tribu, y posteriormente, ante su marido, Rolfe.

Durante el segundo acto, Cahontas intenta encajar en el papel de esposa sumisa tras unirse a Rolfe y dejar su tribu y sus montañas. Sin embargo, su «wild Indian blood» (f. 14) hace que sobre el escenario Cahontas se muestre como un ser volátil, de impulsos violentos, obstinada e incapaz de ser «domada» o domesticada (Brantlinger, 2011). Ella misma se señala diferente a las otras mujeres «de rostro pálido», ostentando con orgullo su calidad de indomable y comparándose con las «aguas del océano»: «True, I am in your power, but not subdued, like the waters of the ocean, am I unconquerable» (f. 17).

Mientras tanto, Rolfe continuamente nos recuerda su conflicto moral al estar emparejado con una «salvaje», sin haber olvidado a su mujer, a la que presume muerta. Para el público del City of London, la trama principal de bigamia serviría tanto para despertar interés morboso como para recordar los cambios de moralidad del momento (Eltis, 2013: 7). En ningún momento se pretendía hacer creer al espectador que Rolfe estaba destinado a estar con Cahontas, más bien lo contrario. Incluso antes del desenlace de la obra, el público era conocedor del final trágico de Cahontas -entre otras razones, porque ya había visto o leído la historia de Pocahontas en numerosas ocasiones (Tilton, 1994: 90)- ${ }^{5}$. Además, la superioridad moral y racial que predominaba en el momento hacía que un matrimonio interracial fuera casi imposible de concebir (MacKenzie, 1995: $185-187)^{6}$.

${ }^{5}$ La primera obra de teatro en explotar la historia de Pocahontas fue The Indian Princess; or, la Belle Sauvage (1808), escrita por James N. Barker. La obra se estrenó en Philadelphia el 6 de abril de 1808, y más de una década después, llegó su adaptación al Drury Lane de Londres el 15 de diciembre de 1820 (Nicoll, 1970: 259). Desde entonces, otras adaptaciones como Pocahontas; or, the Settlers of Virginia (1830), de George Washington Parke Custis, o Pocahontas; or, the gentle savage (1861), de John Brougham, deleitaron al público británico. Otras adaptaciones impresas son la anónima The Chief's Daughter; or, the Settlers in Virginia (1859). Véase una extensa lista cronológica con referencias a la figura de Pocahontas en Gallagher (2015).

${ }^{6}$ Otras obras de teatro decimonónicas en las que podemos observar el conflicto del matrimonio interracial son la pionera The Cataract of the Ganges (1823) de W. T. Moncrieff; Vermuh Kareeda; or, the Fall of Delhi (1857) de J. Towers; o Cora, or, The Octoroon 
Cerca del final de la obra, Cahontas conoce a la verdadera esposa de Rolfe, Mary, quien regresa para reclamar su posición junto a su marido. Ante este giro de acontecimientos, la buena salvaje Cahontas asume su papel marginal en la vida de Rolfe y regresa junto a su padre. Tras arrepentirse públicamente de su transgresión social ( $\mathrm{I}$ am the doomed one, I am the martyr, and now for my native wilds») y justo antes de morir, Cahontas pide el perdón de Mary, la primera esposa de Rolfe e, indirectamente, el del público:

CAHONTAS: (to Mary) Dear Lady, forgive the wrong, the poor untutored Indian maiden did you, and may the Great Spirit forgive me too. Love him as I did, and may your lives for the future be unruffled by a care. Farewell, I'm going from you... (f. 21)

La trama de bigamia es algo habitual en las historias de sensaciones (sensation). Durante mediados de siglo, el contexto colonial da pie a malentendidos y confusiones en los matrimonios; en la ficción, más de un esposo volvía inesperadamente de su puesto en alguna colonia tras haber sido dado por muerto o, como hemos visto en el caso de Cahontas, eran los mismos colonos los que se sorprendían al ver llegar a sus esposas a su pequeño asentamiento en tierra idílica (McAleavey, 2015) ${ }^{8}$. Es así como se entremezcla la trama romántica y colonial tan apreciada por el género de sensaciones.

La adaptación de The Prairie Flower de Gustave Aimard no llamó demasiado la atención de la crítica en su debut en el teatro Britannia, en el East End londinense ${ }^{9}$. A pesar de ello, la obra es un gran ejemplo del tipo de historias sensacionalistas que tan de moda estaban durante los 1860 . Como se ha mencionado anteriormente en este artículo, el género sensacionalista solía centrarse en las desventuras amorosas y trágicas de una

Slave of Louisiana (1861) de J. T. Douglass, representadas por primera vez en los londinenses Drury Lane, Victoria Theatre y Pavilion, respectivamente.

${ }^{7}$ Traducción: «C: (a Mary) Querida señora, perdone a esta pobre, mala e inculta India, y ojalá el Gran Espíritu me perdone también. Ámelo como yo lo he amado, y que sus vidas estén libres de preocupaciones. Adiós, ya les dejo...».

${ }^{8}$ El dramaturgo Tom Taylor explota estos malentendidos en sus comedias de ambientación colonial, especialmente en The Overland Route (1860).

${ }^{9}$ Las citas directas a la obra que se utilizan en esta sección corresponden a los folios numerados del manuscrito original conservado en la British Library de Londres, con referencia British Library Add. MS 52997 P: «The Prairie Flower. Petite drama in one act. Britannia Theatre, 16 noviembre 1860». No existe versión editada impresa del guion. 
protagonista femenina (Diamond, 2003: 4). Así, Zuletta, la joven, buena salvaje cuyo apodo da título a la historia de Aimard, dio el salto del papel al escenario. En el teatro Britannia donde se estrenó por primera vez, Zuletta fue interpretada por la actriz Eliza Clayton, quien se encargaría de seguir las indicaciones del guion y hacer de Zuletta una "poor, unsophisticated girl» (f. 17), a la merced del colono y héroe protagonista Henri Le Grane.

Aunque el guion de la obra The Prairie Flower es anónimo, los más versados en la literatura western de la época pronto identificarían a Gustave Aimard como autor de la historia en la que se basa. Aimard (pseudónimo del francés Olivier Gloux) era conocido por los lectores ingleses, ya que muchas de sus obras habían sido traducidas y adaptadas en los periódicos y revistas del país. Principalmente, sus historias relataban la vida entre «indios» 0 «Indian life», explotando el encuentro entre colonos y nativos americanos en la frontera. En Inglaterra, Aimard fue bautizado como "the great Indian hunter» (Brough, 1860) debido a su continuo uso de sus propias experiencias entre nativos para sus historias. Muchas de sus historias fueron traducidas y publicadas como seriales en las revistas de literatura más importantes de mediados de siglo, como por ejemplo en The Welcome Guest, una publicación semanal que contaba con la colaboración de autores de renombre como George Augustus Sala o Edmund Yates (Oakley, 2013). Hoy en día, Aimard sigue siendo considerado como uno de los fundadores del western, así como un pionero en los escenarios y tramas predilectas del género (Di Gregorio, 2014).

La acción se desarrolla en plena naturaleza, en la colonia establecida por Henri en el oeste americano: un paraje bucólico y silvestre rodeado de grandes rocas e incluso de una catarata (f. 1). El propio Henri nos presenta a Zuletta como su «bright eyed Indian beauty» segundos antes de su llegada, recordándonos así al estereotipo de la «belle sauvage» mencionado. Al entrar en escena por primera vez, la joven nativa corre hacia él y se lanza con devoción a besarle la mano. Momentos después, Zuletta se declara:

ZULETTA: She loves the pale face, he has been kind of her, and she is grateful. You saved her life and she adores you for it. I have lain in my solitary wigwam all night, and gazing at the twinkling stars, have thought 
how like they were to your bright eyes -ah, pale face, you do not know the love I have for you! (f. 3) ${ }^{10}$.

Henri, que no ha olvidado a su verdadero amor (una mujer francesa, de su propia clase social), se muestra esquivo a sus insinuaciones románticas. A pesar de ello, insiste en que Zuletta deje de lado sus maneras «salvajes» y se una a su asentamiento:

HENRI: Now, tell me, are you not tired of your roving life, exposed to every danger? Why do you not quit the mountains and dwell with us?

ZuLETTA: What, quit the mountains? The hills that I have trod so oft. Give up my liberty, to live among the pale faces -no! no! in the wild prairie Zuletta first drew the breath of life, and there will she die (f. 4$)^{11}$.

Incapaz de encontrar su sitio en la «civilización», Zuletta no tiene cabida en la vida del protagonista masculino. Este detalle acentúa la peculiaridad «salvaje» de la nativa, y además le recuerda al público que ella no es como las demás mujeres blancas. A pesar de los esfuerzos de Henri por «civilizar» o «domar» a la salvaje (Hall, 2002; Brantlinger, 2011), Zuletta se muestra reacia. Como Cahontas en la obra del City of London, Zuletta se señala a sí misma como un ser salvaje, incapaz de vivir en la civilización a la cual la invita Henri. Asimismo, tras haber transgredido las leyes morales de la época y haberse «casado» con Henri a pesar de él estar prometido a otra, Zuletta asume su final trágico. Durante la «sensation scene» que marca el final de la obra, Zuletta se encuentra en su lecho de muerte; la buena salvaje sacrifica su vida con tal de que la civilización progrese. En otras palabras, Zuletta explica su error al confundir su posición y une a Henri con su verdadero amor, Eugenie:

ZULETTA: He had not then a wife, she wed him out of love, he did not say that he had already chosen one of his heart, and so the poor girl hoped

${ }^{10}$ Traducción: «Z: Ella ama al rostro pálido, él ha sido amable con ella y ella está agradecida. Usted le salvó la vida y por ese motivo ella le adora. He yacido en mi tienda solitaria durante toda la noche, y tras admirar el titileo de las estrellas, he pensado en cómo se parecen a sus ojos radiantes -ioh, rostro pálido, no sabe usted el amor que le tengo!-».

${ }^{11}$ Traducción: «H: Dime, ¿no estás cansada de tener una vida errante, expuesta a todo tipo de peligros? ¿Por qué no dejas las montañas y te unes a nosotros? Z: ¿Qué, dejar las montañas? Las colinas por las que tanto he caminado. Abandonar mi libertad para vivir entre los rostros pálidos... ¡no! ¡no! En la pradera salvaje Zuletta tomó su primer aliento, y ahí morirá». 
that one day he might be hers -at length she discovered he was about to wed, all her hopes were plighted... she resolved to leave her native hills... and die, as I shall, of a broken heart... Lady, Monsieur. Your hands (kisses them) should that poor Indian girl I spoke of live, may she act as I do now. May you be happy (f. 19) ${ }^{12}$.

Si bien el género melodramático está caracterizado por sus inesperados y abruptos finales felices para los protagonistas, es cierto que las convenciones no se muestran tan bondadosos con la buena salvaje. Williams (2015: 2) sugiere que el final feliz en el melodrama de mediados de siglo no pretende servir como "escapismo», sino que evidencia un claro cambio en el paradigma cultural:

it is a sign of the struggle to believe in a system of justice and human law that is nowhere yet to be seen in the real world; and a sign of the attempt, on the part of the common (and, later, middle-class) people, to learn how to navigate the defiles of modernity.

Sin embargo, en el caso de la buena salvaje, su final trágico tiene un cometido diferente: las muertes de Cahontas y de Zuletta restauran el orden moral y social en la colonia, haciendo que tanto Rolfe como Henri sean absueltos por su transgresión. Tal y como nuestras protagonistas nos muestran, para la buena salvaje del teatro melodramático la absolución solo llega tras su sacrificio desinteresado. De esta manera, la muerte de la buena o bella salvaje se asemeja a la de la "fallen woman», cuyo final trágico busca impartir una lección en moralidad. Asimismo, en la representación de las buenas salvajes se refuerzan las desigualdades sociales entre razas, evidenciando la diferencia de estatus entre el colono y la mujer nativa. Tanto Cahontas como Zuletta reverencian al hombre blanco:

12 Traducción: «Z: En ese momento él no tenía esposa, ella se casó con él por amor, él no dijo que su corazón ya había elegido a otra, así que la pobre chica mantuvo la esperanza de que algún día fuera suyo -al final descubrió que él estaba a punto de casarse, todas sus esperanzas se vieron comprometidas... ella decidió dejar las colinas que fueron su hogar... y morir, como lo haré yo, con el corazón roto... Señora, Monsieur. Sus manos (las besa) si esa pobre India viviera, ojalá actuara como yo ahora. Que sean felices». 
CAHONTAS: (to Rolfe) no tongue but yours should crush the heart so entirely devoted to you (f. 20) ${ }^{13}$.

ZuletTA: [a Henri] Zuletta has no Friends -save you- and you are so far above her that she dare not hope you will always be one (f. 4$)^{14}$.

\section{CONCLUSIONES}

Como hemos comentado en estas páginas y a modo de conclusión, la historia del personaje tipo de la buena salvaje contribuye al orden social y moral. Gracias al poder manipulador del teatro, los ejemplos de Cahontas y Zuletta -dos entre muchos otros- permiten que el público de clase trabajadora procese de otra manera los cambios sociales que acontecían con tantísima velocidad durante los 1860. Tanto el City of London como el Britannia eran conocidos por contar con el patrocinio de los vecinos, gente trabajadora y de baja clase social que residía en el este londinense (Davis y Emeljanow, 2004: 96; Norwood, 2009: 135). La buena salvaje provoca una respuesta emocional en el espectador, pero quizá no solo de compasión, sino también de rechazo. Tal y como se ha argumentado en las secciones anteriores, la buena salvaje se construye a través de los deseos del hombre blanco; no solo es una «sierva» o ayudante del colono, sino también una fuente de autoconfianza tanto para él como para los espectadores. Quizá, como hemos señalado, la buena salvaje era llevada a escena para provocar la reflexión del público y, así, justificar las misiones coloniales en pos de la civilización.

\section{BIBLIOGRAFÍA CITADA}

ALtick, R. (1978): The Shows of London. Cambridge (Mass.)-London: The Belknap Press of HUP.

BнABHA, H. K. (1994): The Location of Culture. London-New York: Routledge. BRANTLINGER, P. (2011): Taming Cannibals: Race and the Victorians. New YorkLondon: Cornell University Press.

${ }^{13}$ Traducción: «C: (a Rolfe) solo tu lengua debería destrozar un corazón tan devoto a ti como este».

${ }^{14}$ Traducción: «Z: Zuletta no tiene amigos -a excepción de usted-, y usted es tan superior a ella que ella ni se atrevería a pensar que lo será para siempre». 
BRough, R. (1860): The Welcome Guest, a journal of recreative literature, London: Houlston and Wright, v.

ChAmBers, C. (2011): Black and Asian Theatre in Britain: A history. New York: Routledge.

CURRY, J. K. (2019): «Spectacle and Sensation in The Octoroon/An Octoroon». Nineteenth Century Theatre and Film, 46.1, 38-58.

DALY, N. (2013): Sensation and Modernity in the 1860s. Cambridge: CUP [2009].

DAVIS, T. C. (2012): The Broadview Anthology of Nineteenth-century British Performance. London: Broadview Press.

DAVIS, J. y EMELJANOW, V. (2004): «Victorian and Edwardian audiences». En Powell, K. (ed.): The Cambridge Companion to Victorian and Edwardian Theatre. Cambridge: CUP, 93-108.

Diamond, M. (2003): Victorian Sensation: Or the spectacular, the Shocking and Scandalous in Nineteenth-century Britain. London: Anthem Press.

DickENS, C. (1853): «The Noble Savage». Household Words, VII, 168, 337-339.

Di GREgORIO, L. (2014): Wilderness et Western. L'Ouest fictionnel chez Gustave Aimard et Emilio Salgari. Liège: Presses Universitaires de Liège.

Dyer, G. (2008): «The Transatlantic Pocahontas». Nineteenth-Century Contexts, $30.4,301-322$.

Ellingson, T. (2011): The Myth of the Noble Savage. Berkeley-Los Angeles-London: University of California Press.

Eltis, S. (2013): Acts of Desire: Women and Sex on Stage 1800-1930. Oxford: OUP.

FLINT, K. (2009): The Transatlantic Indian, 1776-1930. New Jersey: Princeton University Press.

Gallagher, E. J. (2015): The Pocahontas Archive (en línea: <http://digital.lib.lehigh.edu/trial/pocahontas/index.php>, consulta: 24 de mayo de 2021).

Green, R. (1975): "The Pocahontas Perplex: The Image of Indian Women in American Culture». The Massachusetts Review, 16.4, 698-714.

HaLl, C. (2002): Civilising Subjects: Metropole and Colony in the English Imagination 1830-1867. Chicago: University of Chicago Press.

HARdT, M. y Negri, A. (2002): Imperio. Barcelona: Paidós.

JÁuregui, C. A. (2008): Canibalia. Canibalismo, calibanismo, antropogafia cultura y consumo en América Latina. Madrid: Iberoamericana. 
Lyytinen, M. (2009): «The Pocahontas Myth and Its Deconstruction in Monique Mojica's Play». En Wilmer, S. E. (ed.): Native American Performance and Representation. Tucson: University of Arizona Press.

Mabilat, C. (2008): Orientalism and Representations of Music in the Nineteenth-century British Popular Arts. New York: Routledge.

MacKenzie, J. (1995): Orientalism: History, Theory and the Arts. Manchester: MUP.

McAleavey, M. (2015): The Bigamy Plot. Sensation and Convention in the Victorian Novel. Cambridge: CUP.

MCCLINTOCK, A. (1995): Imperial Leather: Race, gender and sexuality in the colonial context. New York-London: Routledge.

MeER, S. (2018): «Melodrama and Race». En Williams, C. (ed.): The Cambridge Companion to English Melodrama. Cambridge: CUP, 192-208.

Moore, G. (2002): «Reappraising Dickens's "Noble Savage"». Dickensian, 98, 236-243.

Nicoll, A. (1970): A History of English Drama, 1660-1900. Vol. IV. Cambridge: CUP.

Norwood, J. (2009): «The Britannia Theatre: Visual Culture and the Repertoire of a Popular Theatre». En Heinrich, A. et al. (eds.): Ruskin, the Theatre and Victorian Visual Culture. London: Palgrave Macmillan, 135-143.

OAKLEY, M. (2013): The Welcome Guest. A Magazine of Recreative Reading for All. The Victorian Web: Literature, history \& culture in the age of Victoria (en línea: <https://victorianweb.org/periodicals/welcomeguest/oakley.html>, consulta: 24 de marzo de 2021).

Pal-Lapinski, P. (2005): The Exotic Woman in Nineteenth-Century British Fiction and Culture: A Reconsideration. Durham: University of New Hampshire Press.

PratT, M. L. (1992): Imperial Eyes: Travel Writing and Transculturation. New York: Routledge.

QuRESHI, S. (2011): Peoples on Parade: Exhibitions, Empire, and Anthropology in Nineteenth-Century Britain. Chicago-London: The University of Chicago Press.

SAID, E. (1978): Orientalism. London: Routledge.

SÁNCHEZ-GómEZ, L. A. (2013): «Human Zoos or Ethnic Shows? Essence and Contingency in Living Ethnological Exhibitions». Culture \& History Digital Journal, 2.2, e022 (https://doi.org/10.3989/chdj.2013.022). 
SPIVAK, G. C. (2015): «Can the Subaltern Speak?». En Williams, P. y Chrisman, P. (eds.): Colonial Discourse and Post-Colonial Theory: A Reader. London: Routledge, 66-111 [1993].

StoneR, R. (2003) «Pocahontas, Mother of the New Woman in Charlotte Barnes's The Forest Princess». En Manuel, C. y Derrick, P. S. (eds.): Nor Shall Diamond Die: American Studies in Honour of Javier Coy. Valencia: Universitat de València, 507-516.

TAYLOR, C. (1961): «Notes on American Negro Reformers in Victorian Britain». Bulletin British Association for American Studies, 2, 40-51.

TILTON, R. S. (1994): «The Pocahontas Narrative in the Era of the Romantic Indian». En Tilton, R. S.: Pocahontas: The Evolution of an American Narrative. Cambridge: CUP, 58-92.

VoskuIL, L. M. (2004): Acting Naturally: Victorian theatricality and authenticity. Charlottesville: University of Virginia Press.

WATERS, H. (2007): Racism on the Victorian Stage: Representation of Slavery and the Black Character. Cambridge: CUP.

Williams, C. (2015): «Melodrama». En Hughes, L. K. et al. (eds.): The Encyclopedia of Victorian Literature, 1-9 (https://doi.org/10.1002/9781118405376 .wbevl206).

ZITER, E. (2003): The Orient on the Victorian Stage. Cambridge: CUP.

Victoria PUCHAL TEROL Universidad Católica de Valencia "San Vicente Mártir» mv.puchal@ucv.es https://orcid.org/0000-0002-9692-259X 